\title{
AN INTEGRATED METHOD OF AHP FORWARD-BACKWARD PLANING FOR DETERMINING DEVELOPMENT DIRECTIONS OF MILITARY EQUIPMENT
}

\author{
Sun Hongcai and Li Ming \\ Beijing Institute of Decision sience and Mangement. \\ N-24 Tai ping Road, Beijing, 100850, P.R.China \\ Email: hcs@cenpok.net
}

\begin{abstract}
To plan a direction of the development for a certain period in future is the main topic of the development strategy of the weapon equipment. For its prescriptive, foreseeable and directional characters, there are two main purposes of the plan: first, to study its rationality, feasibility and profitability, and second, through the concerned methods of the planning, to acquire an objective system. Therefore, in order to determine a direction, it is of first importance to establish an either foreseeable or feasible objective system about the general direction of the development. And meanwhile, relying on the system, to analyze the degree of the effects which each object brings to the general direction of the development of a certain kind of weapon equipment. To meet with the requirements that mentioned above, this article will mainly discuss the progress of the Forward Plan, the Backward Plan and the Combined Forward $h$ Backward Plan. And it will cover the planning strategy of the direction of the development, the objective system of the direction of the development, the basic steps of analyzing the direction of the development, and the mathematics model of the direction of the development.
\end{abstract}

Keywords military equipment; development strategy;

Objective systems; forward-backward planing; AHP 